\title{
MULTI-CRITERIA DECISION MAKING FOR IDENTIFICATION OF UNBALANCED BIDDING
}

\author{
Limin $\mathrm{SU}^{1}$, Tianze $\mathrm{WANG}^{2}$, Huimin $\mathrm{LI}^{\star 3,4,5}$, Yongchao $\mathrm{CAO}^{3,4,5}$, Lunyan $\mathrm{WANG}^{3,4,5}$ \\ ${ }^{1}$ School of Management and Economics, North China University of Water Resources and Electric Power, \\ 450046 Zhengzhou, China \\ ${ }^{2}$ School of Mathematics and Statistics, North China University of Water Resources and Electric Power, \\ 450046 Zhengzhou, China \\ ${ }^{3}$ Department of Construction Engineering and Management, North China University \\ of Water Resources and Electric Power, 450046 Zhengzhou, China \\ ${ }^{4}$ Henan Key Laboratory of Water Environment Simulation and Treatment, 450045, Zhengzhou, China \\ ${ }^{5}$ Collaborative Innovation Centre of Water Resources Efficient Utilization and Protection Engineering, \\ 450045, Zhengzhou, China
}

Received 28 April 2019; accepted 29 July 2019

\begin{abstract}
Unbalanced bidding is a serious problem in the competitive bidding practices of construction projects. Identification and prevention of unbalanced bidding is an important and complexity task for owners. This paper aims to propose an identification model of unbalanced bidding from multi-criteria decision making (MCDM) perspective. The VIKOR method is employed to detect unbalanced bidding, in which the line items and bidders are considered as criteria and alternatives in MCDM, respectively. And the engineer's estimated price is chosen as evaluation benchmarking. Then relative distances between engineer's estimated price and each bidding unit price are calculated to build decision matrix. The weights of factors are determined using entropy weight method. To illustrate the effectiveness of the proposed model, an application example is tested in detecting unbalanced bidding. Finally, the sensitivity analysis about VIKOR method is given. It shows that the presented model would provide a robust decision making support for owner in identifying unbalanced bidding.
\end{abstract}

Keywords: project management, unbalanced bidding, multi-criteria decision making, VIKOR.

\section{Introduction}

In the construction industry, unbalanced bidding is in common that contractors use it to win the bidding and achieve a higher profit (Hoogenboom, Dale, \& Martel, 2006; Cattell, Bowen, \& Kaka, 2007; Hyari, 2016). Hyari, Tarawneh, and Katkhuda (2016) gave an illustration for unbalanced bidding, which stated the unbalanced bidding is that the bidder changes the prices of line items in bill of quantity through increasing the prices of some line items and reducing the prices of other line items with the total bid price remaining constant (Hyari et al., 2016). And the types of unbalanced bidding mainly are front-end loading and quantity error exploitation (Hyari, 2016; Hyari et al., 2016).

Recently, many research for unbalanced bidding have been conducted (Christodoulou, 2008; Liu, Lin, \& Zang,
2009; Afshar \& Amiri, 2010a; Arditi \& Chotibhongs, 2009; Cattell, Bowen, \& Kaka, 2010; Renes, 2011; Mandell \& Nystrom, 2011; Stramarcos \& Cattell, 2013; Afshar \& Amiri, 2010b; Hyari, 2017a, 2017b). They are focused on three aspects: development of optimization models (Burnett \& Wampler, 1998; Son, Mack, \& Mattila, 2006; Christodoulou, 2008; Liu et al., 2009; Afshar \& Amiri, 2010a, 2010b; Mandell \& Nystrom, 2011; Cattell, 2013; Cattell, Bowen, \& Kaka, 2008; Cattell, Bowen, \& Kaka, 2004; Bajari, Houghton, \& Tadelis, 2014), the ethics of unbalanced bidding (Cattell et al., 2010) and identification and prevention of unbalanced biding (Wang, 2004; Renes, 2011; Arditi \& Chotibhongs, 2009; Hyari, 2016). For the first aspect, Gates (1967) presented the early optimization model of unbalanced bidding, and later, modified and/

${ }^{*}$ Corresponding author. E-mail: lihuimin3646@163.com 
or improved models were developed (Stark, 1968, 1972, 1974). Afshar and Amiri (2010a, 2010b) presented a fuzzy linear programming model to optimization unbalanced bidding prices. Cattell, Bowen, and Kaka (2011) employed an effective unbalanced bidding model using cumulative prospect theory. The model manages to identify a combination of item prices that is expected to generate a high profit. For the second aspect, Cattell et al. (2010) said that the owners have the right to reject an unbalanced bidder, but they have no right to dictate the bidder how to pricing the work items. In free-market circumstance, the bidder present the item price should be dependent on the construction technique (Cattell et al., 2010). Arditi and Chotibhongs (2009) argued that unbalanced bidding is unethical. $84 \%$ of construction participants classified unbalanced bid as an unethical active (Doran, 2004). And for the third aspect, Wang (2004) presented an identification unbalanced bid method with electronic-based procedure. In this method, when the owner suspects a list item is unbalanced, the owner can adjust the unit price according to the qualified bidder's unit prices and estimated price from the owner. Renes (2011) argued that it is possible to eliminate or minimize the occurrence of unbalanced bidding by requiring bidders to estimate the actual quantities. Arditi and Chotibhongs (2009) built an identification model to find the unbalanced bidder, according to comparison of unit prices given by engineer's estimates and unit prices from the bidders. They provided the identification process of unbalanced bid and demonstrated the specific application of the model. However, according to this method, the identification of unbalanced bids is more resource demanding. In order to prevent the unbalanced biding, Hyari (2016) presented a model by readjusting the project unit prices to average unit prices of all bids. This reduces the influence of any unreasonably unit price.

The existed research shows that unbalanced bidding commonly occurs in construction industry, and it has a serious impact for owner (Yin, Lu, \& Li, 2010; Abdulrahman, Hanid, \& Xiang, 2014). The contract awarded an unbalanced bidding is likely to result in overrun of project cost (Arditi \& Chotibhongs, 2009; P. P. Shrestha, K. Shrestha, \& Joshi, 2012). Chotibhongs (2011) argued that unbalanced bidding in construction sector is a serious and unethical issue. In public procurement, unbalanced bidding destroyed the fairness of the bidding competitive and increases the project owner's cost (Renes, 2012). So, how to detect the unbalanced bidding is a challenging task faced by theoretical researchers and practical actors (Stramarcos \& Cattell, 2013; Manzo \& Tell, 1997). Hyari et al. (2016) designed identification of unbalanced bidding model from risk perspective. The variation quantities from the historical estimated quantities projects were used as benchmark of future deviation in the bidding project. However, each construction project is unique, which presents challenges to apply that model. In addition, in order to reduce the effects of unbalanced bids on owners in the construction industry, Hyari (2017b) presented some countermeasures for owners and bidding officials. These include both preventive measures and remedial measures, which can help owners to prevent and mitigate the impacts of unbalanced bids. These countermeasures also provide support to bidding officials to protect public interests and ensure an efficient use of the public money. The identification of unbalanced bidding is acted in uncertainty environment; An et al. (2018) developed an identification model based on unascertained mathematical theory.

Although the researchers have made a rich support to detect unbalanced bid in bidding evaluation process, there still suffer from some shortcomings: (1) The concept of unbalanced bids has not a clear boundary between "unbalanced" and "balanced", (2) the existing identification approach ignored the variety and complexity of factors affecting unbalanced bidding, and (3) using the existing identification approach of unbalanced bidding, owners generally reject the bidders once the seriously unbalanced bid happens to them, and don't consider the reason leading to unbalanced bid. This study aims to develop an appropriate method for identifying unbalanced bidding from a Multi-criteria decision-making (MCDM) perspective. The main contributions of this paper are as follows: (1) the identification problem of unbalanced bidding is innovatively analyzed using MCDM method, in which the line items and bidders in unbalanced bidding are considered as criteria and alternatives in MCDM, respectively. And the engineer's estimated price is chosen as evaluation benchmarking. (2) The VIKOR (VlseKriterijumska Optimizacija I Kompromisno Resenje) method is applied to identify unbalanced bidding, since it considers all bidders' quotes and single bidder' quote, simultaneously, which can give a more reasonable result for owners. (3) The sensitivity analysis about VIKOR method shows its robustness of decision-making.

The remainder of this paper is structured as follows. Section 1 builds a VIKOR based decision making support model for detection of unbalanced bidding. In Section 2, a case study is shown the practicability and effectiveness of the proposed method. Conclusions are drawn in the final section.

\section{Methodology for identification of unbalanced biding}

\subsection{Identifying unbalanced biding from MCDM perspective}

Unbalanced bids, adopted by bidders in bidding process, will lead to increase sharply costs in engineering construction and bring to investment risks for owners. Therefore, there is a need to develop a new technology for owner to identify and prevent unbalanced bids. The identification of unbalanced bids is a hard and complex task for owners, since the concept of unbalanced bids has not a clear boundary between "unbalanced" and "balanced", and the identification of unbalanced bids in practical engineering construction is affected by various factors. 
Normally, different construction enterprises use different construction techniques, methods, material purchasing prices, and so on. Therefore, the unit prices of the same work items they presented may vary. In this paper, engineer's estimated price is chosen as the evaluation criterion and the bidding unit-price of the bidders will be compared with the estimated price. In order to identify the unbalanced bidding, constructing mathematical model to identify unbalanced bidding is a usually way.

MCDM approach is used to solve a kind problem that has many alternative options and several factors affecting the choice of alternative options. And the MCDM problem is to get an appropriate option using an appropriate decision making method. For a given unbalanced bidding problem, let $X=\left\{X_{1}, X_{2}, \ldots, X_{n}\right\}$ be the set of bidders, $L=\left\{l_{1}, l_{2}, \ldots, l_{m}\right\}$ be the set of line items, $x_{i j}(i=1,2, \ldots, n ; j=1,2, \ldots, m)$ be the unit price given from the $i$ th bidder with respect to the $j$ th line item, and $W=\left\{w_{1}, w_{2}, \ldots, w_{m}\right\}$ be the weight vector of the line items with $0 \leq w_{j} \leq 1$ and $\sum_{j=1}^{m} w_{j}=1$. Also we assume that $x_{j}^{0}(j=1,2, \ldots, m)$ is the $j$ th engineer's estimated price. The identification of unbalanced bidding is to rank bidders according to the maximum deviation between each bidding unit-price and the corresponding engineer's estimated price. The bidding information is shown as a matrix $X=\left(x_{i j}\right)_{n \times m}$, where bidders are seen as alternatives or objects and line items is criteria or factors in MCDM, respectively. As mentioned above, it is reasonable that detecting unbalanced bid is seen as a MCDM problem. In following section, we introduce VIKOR to identify unbalanced bid problem.

\subsection{Determination of the weights of line items}

The weight of line item represents the possibility of unbalance in the bidding. Determination of the line items' weights is crucial to the reliability of identifying unbalanced bidding. The proper assessment of the line items' weights plays a dominant role during decision making processes.

In the process of assessing the bidder's unit prices, the greater the difference between engineer's estimate price and the unit price from the bidder's offer, the greater the likelihood that the line item will be unbalanced, and information entropy may just show this difference. Information entropy is defined as (Lan, Yang, \& Huang, 2017; Shemshadi, Shirazi, Toreihi, \& Tarokh, 2011; Wu, Duan, Zuo, Zhao, \& Tang, 2017):

$$
G_{j}=-\frac{1}{\ln m} \sum_{j=1}^{n} g_{i j} \ln g_{i j}, i=1,2, \ldots, n,
$$

where $g_{i j}$ is the information that to be measured.

And $g_{i j}$ can be determined as follows:

$$
g_{i j}=d_{i j} / \sum_{j=1}^{m} d_{i j}
$$

and assume that $g_{i j} \ln g_{i j}=0$ when $g_{i j}=0$, where $d_{i j}$ is the difference between engineer's estimated price and bidding unit-price for the $i$ th bidder with respect to the $j$ th line item, that is $d_{i j}=\left|x_{i j}-x_{j}^{0}\right|$.

Therefore, the entropy weight of $w_{j}$ can be calculated as follows:

$$
w_{j}=\frac{1-G_{j}}{m-\sum_{j=1}^{m} G_{j}}
$$

with $0 \leq w_{j} \leq 1$ and $\sum_{j=1}^{m} w_{j}=1$, and the weight vector is
$W=\left\{w_{1}, w_{2}, \ldots, w_{m}\right\}$.

\subsection{VIKOR approach for identification of unbalanced bidding}

The VIKOR model is an effective method in MCDM problem, in which the positive and negative ideal points are defined, and the relative distance between each criteria value and standard value is determined. If $D=y_{i j}-y_{0}$ represents the difference between each criteria value $y_{i j}$ and the standard value $y_{0}$, then the relative distance is a ratio of the difference $D$ and the standard value $y_{0}$. According to each relative distance, a weighted compromise ranking used to express the importance of each alternative is determined. In other words, the VIKOR method can make out the compromise rankings and alternatives in accordance with the assessment of "closeness" to the "ideal values" (Liu \& Qin, 2017; Dong, Yuan, \& Wan, 2017; Lan et al., 2017). The steps of the compromise ranking are as follows.

Step 1: Define the positive and negative ideal points. If the evaluation matrix is $A=\left(a_{i j}\right)_{m \times n}$, then for benefit criteria, the positive and negative points are

$$
\begin{aligned}
& a_{j}^{*}=\max _{i}\left\{a_{i j}\right\} ; \\
& a_{j}^{-}=\max _{i}\left\{a_{i j}\right\},
\end{aligned}
$$

and for cost criteria, the positive and negative points are

$$
\begin{aligned}
& a_{j}^{*}=\max _{i}\left\{a_{i j}\right\} ; \\
& a_{j}^{-}=\max _{i}\left\{a_{i j}\right\} .
\end{aligned}
$$

Step 2: Calculate the values of $S_{j}$ and $R_{j}, j=1,2, \ldots, m$, as follows:

$$
\begin{aligned}
& S_{j}=\sum_{i=1}^{n} w_{i} \frac{a_{j}^{*}-a_{i j}}{a_{j}^{*}-a_{j}^{-}} ; \\
& R_{j}=\max _{i}\left(w_{i} \frac{a_{j}^{*}-a_{i j}}{a_{j}^{*}-a_{j}^{-}}\right),
\end{aligned}
$$

where $w_{1}, w_{2}, \ldots, w_{n}$ are the weights of all criteria, $S_{j}$ represents the group utility and $R_{j}$ the individual regret.

Step 3: Compute the values of $Q_{j}, j=1,2, \ldots, m$ :

$$
Q_{j}=v\left(\frac{S_{j}-S^{+}}{S^{-}-S^{+}}\right)+(1-v)\left(\frac{R_{j}-R^{+}}{R^{-}-R^{+}}\right),
$$

where $S^{+}=\min _{i} S_{j}, S^{-}=\max _{i} S_{j}, R^{+}=\min _{i} R_{j}, R^{-}=\min _{i} R_{j}$ 
and $v$ is the subjective weight, when $v>1 / 2$, the group utility gets more support, when $v<1 / 2$, the individual regret gets more support, and when $v=1 / 2$, both of them get the same support.

Step 4: Rank the alternatives using the values of $Q_{j}$.

Based on the mentioned above, the main steps of detecting unbalanced bid based on VIKOR method and information entropy weight method could be described as follows.

Step 1: Normalize the evaluation information matrix. The objective is to evaluate the different bidding unit price with respect to the engineer's estimate price. Using $a_{i j}=\frac{\left|x_{i j}-x_{j}^{0}\right|}{x_{j}^{0}}$, where $x_{i j}$ is the bidding unit price from the $i$ th bidder with respect to the $j$ th line item, the normalized matrix is obtained:

$$
A=\left(a_{i j}\right)_{m \times n} .
$$

Step 2: Determine the best $a_{j}^{*}$ and the worst $a_{j}^{-}$values of all criteria, $j=1,2, \ldots, n$.

For benefit criteria:

$$
\begin{aligned}
& a_{j}^{*}=\max _{i}\left\{a_{i j}\right\} ; \\
& a_{j}^{-}=\min _{i}\left\{a_{i j}\right\} .
\end{aligned}
$$

For cost criteria:

$$
\begin{aligned}
& a_{j}^{*}=\min _{i}\left\{a_{i j}\right\} ; \\
& a_{j}^{-}=\max _{i}\left\{a_{i j}\right\} .
\end{aligned}
$$

Since the value of $a_{i j}$ is the relative distance between bidding unit-price and engineer's estimated price, the smaller the value of $a_{i j}$, the more balanced the bidding unit-price will be. Therefore, the best and the worst values are determined using Eqn (6).

Step 3: Determine the weight based on the entropy weight. Using Eqns (1)-(3), the weights of all line items can be calculated.

Step 4: Compute the values of $S_{i}$ and $R_{i}, i=1,2, \ldots, m$ using Eqns (7) and (8):

$$
\begin{aligned}
& S_{i}=\sum_{j=1}^{n} w_{j}\left[\frac{a_{j}^{*}-a_{i j}}{a_{j}^{*}-a_{j}^{-}}\right] ; \\
& R_{i}=\max _{j}\left[w_{j}\left(\frac{a_{j}^{*}-a_{i j}}{a_{j}^{*}-a_{j}^{-}}\right)\right],
\end{aligned}
$$

where $S_{i}$ denotes the distance rate of the $i$ th bidder to the positive ideal solution, and $R_{i}$ represents the distance rate of the $i$ th bidder to the negative ideal solution. Also, $w_{j}$ are the weights of line items, which express relative importance among all line items.
Step 5: Compute the values of compromise value $Q_{i}$, $i=1,2, \ldots, m$ using Eqn (9):

$$
Q_{i}=v \frac{S_{i}-S^{*}}{S^{-}-S^{*}}+(1-v) \frac{R_{i}-R^{*}}{R^{-}-R^{*}},
$$

where $S^{-}=\max _{i} S_{i}, S^{*}=\min _{i} S_{i}, R^{-}=\max _{i} R_{i}, R^{-}=\min _{i} R_{i}$, and $v \in[0,1]$ is the weight of the strategy of the "the majority of criteria" (or "the maximum group utility").

Step 6: Rank all the alternatives according to the values of $Q_{i}$ calculated in Step 5, we can rank the bidders and identify unbalanced bids.

Step 7: If the following two conditions are satisfied concurrently, then scheme with a minimum value of $Q$ in ranking is considered as the optimal compromise solution. For example:

C1. The alternative $Q\left(A^{(1)}\right)$ has an acceptable advantage if $Q\left(A^{(2)}\right)-Q\left(A^{(1)}\right) \geq 1 / n-1$, where $A^{(2)}$ is the alternative with the second position in the ranking list and is the number of alternatives.

$C 2$. The alternative $Q\left(A^{(1)}\right)$ is the stable within the decision making process if it is also best ranked in $S_{i}$ and $R_{i}$.

Step 8: Select the best alternative by choosing $Q\left(A^{(m)}\right)$ as a best compromise solution with the minimum value of $Q_{i}$ regarding above conditions.

The above algorithm is also shown in Figure 1 as follows.

\section{Case study}

In this section, the proposed model is illustrated via an example. This example is adapted from Arditi and Chotibhongs (2009). The bill of quantity, bidders' bid quotation and engineer's estimated price of the project are shown in Table 1.

There are five qualified construction bidders for this project, and their bidding unit prices are displayed in Table 1. In this case, the bidding unit price from the $i$ th bidder with respect to the $j$ th list item is $x_{i j}, i=1,2, \ldots, 5$, $j=1,2, \ldots, 17$, and the $j$ th engineer's estimated price is $x_{j}^{0}, j=1,2, \ldots, 17$. As shown in Table 1 , although the total prices of the five bidders are closed, the unit prices of some items proposed by them are quite different. For example, the item 100 of the bidder 1 in Table 1 is 5000, while that of the bidder 5 is 17589 which is more than three times of the quotation of the bidder 5 .

For the above bidding problem, applying VIKOR presented in Section 1, the bidder who using the most unbalanced bidding should be identified. The steps of the identification process are given below.

Step 1: Normalize the bidding unit-price matrix as following form 


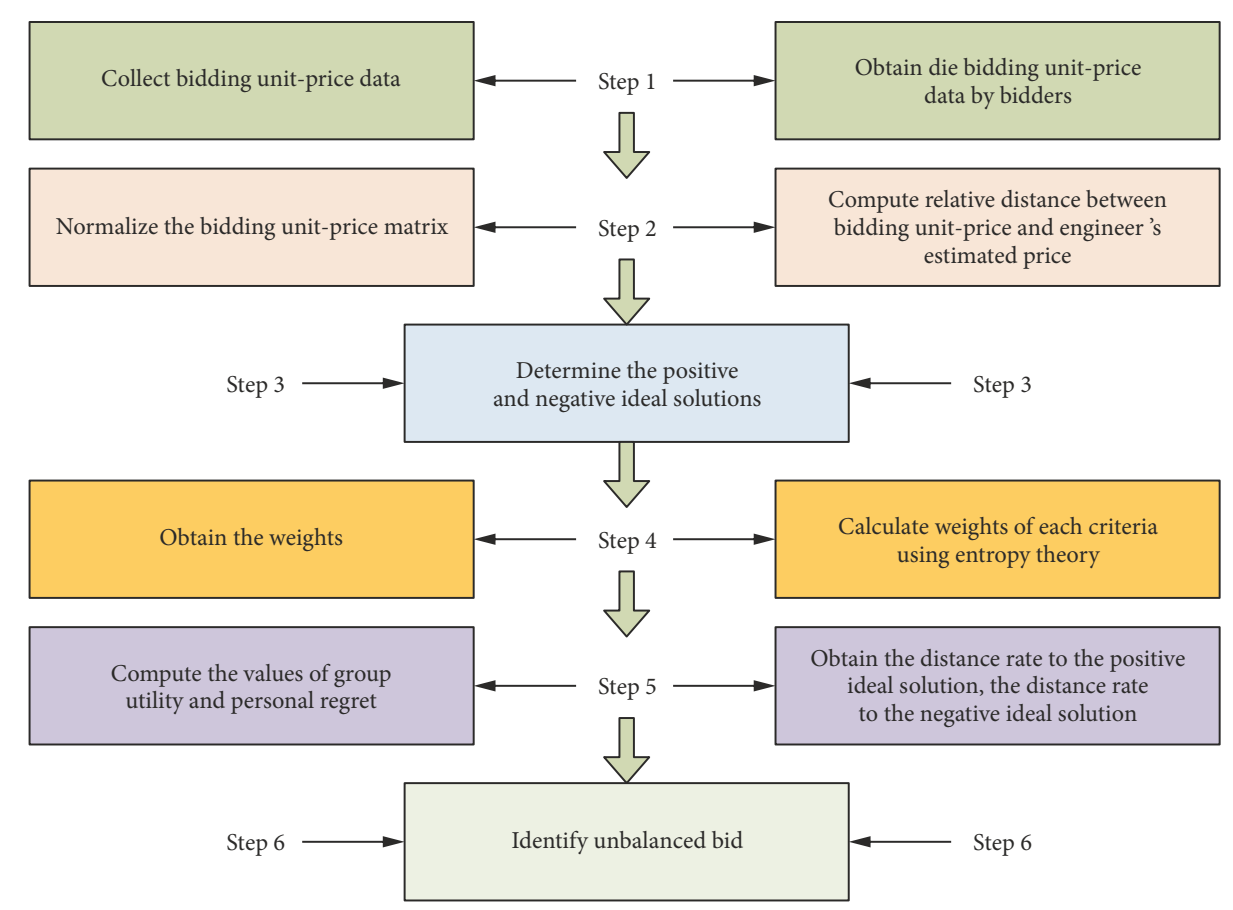

Figure 1. The framework of VIKOR model for identification of unbalanced bidding

$A=\left(a_{i j}\right)_{5 \times 17}=\left(\begin{array}{ccccc}0.6667 & 0.0929 & 0.0811 & 0.1036 & 0.1726 \\ 0.0132 & 0.8571 & 0.0764 & 0.0217 & 0.0448 \\ 0.0724 & 0.0648 & 0.0196 & 0.0168 & 0.0257 \\ 0.1250 & 0.1260 & 0.1522 & 0.0995 & 0.1328 \\ 1.0000 & 0.5000 & 0.0832 & 0.0218 & 0.0000 \\ 0.0567 & 0.1175 & 0.1617 & 0.2117 & 0.1617 \\ 0.5506 & 0.4382 & 0.0893 & 0.0138 & 0.0022 \\ 0.0578 & 0.0033 & 0.0416 & 0.0073 & 0.0002 \\ 0.0067 & 0.0811 & 0.1459 & 0.1401 & 0.1815 \\ 0.0118 & 0.4000 & 0.1394 & 0.1038 & 0.0924 \\ 0.0086 & 0.0212 & 0.1026 & 0.1134 & 0.1300 \\ 0.0806 & 0.1056 & 0.0297 & 0.0309 & 0.0256 \\ 0.8667 & 0.1467 & 0.1000 & 0.1333 & 0.1000 \\ 0.0639 & 0.1121 & 0.1471 & 0.0732 & 0.0175 \\ 0.0904 & 0.1819 & 0.2194 & 0.1358 & 0.1219 \\ 0.0319 & 0.0894 & 0.1242 & 0.1653 & 0.1294 \\ 0.0683 & 0.0232 & 0.0426 & 0.1398 & 0.1290\end{array}\right)^{T}$,

where $a_{i j}=\frac{\left|x_{i j}-x_{j}^{0}\right|}{x_{j}^{0}}, x_{i j}$ is bidding unit-price from the $i$ th bidder with respect to the $j$ th line item, and $x_{j}^{0}$ is the $j$ th engineer's estimated price, as shown in Table 1 , where $i=$ $1,2, \ldots, 5, j=1,2, \ldots, 17$.

Step 2: Based on the normalized matrix $A$, the positive and negative ideal solutions can be determined according to Eqn (6) as follows:

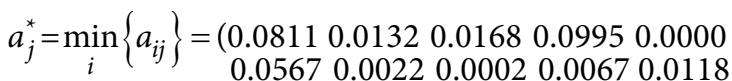

$$
\begin{aligned}
& \begin{array}{llll}
0.0086 & 0.02560 .1000 & 0.0175 & 0.0904
\end{array} \\
& 0.0319 \text { 0.0232); }
\end{aligned}
$$

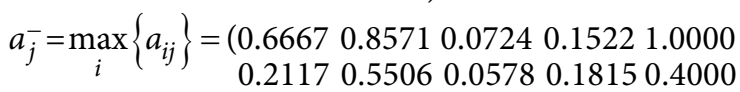

$$
\begin{aligned}
& \begin{array}{llllllll}
0.1300 & 0.1056 & 0.8667 & 0.1471 & 0.2194
\end{array} \\
& 0.16530 .1398) \text {. }
\end{aligned}
$$

Step 3: From Eqns (1)-(3), the weight vector of line items are determined as follows:

$$
\begin{aligned}
& w=\left(\begin{array}{llllll}
0.0706 & 0.1780 & 0.0315 & 0.0016 & 0.1322 & 0.0133
\end{array}\right. \\
& \begin{array}{llllll}
0.1118 & 0.1080 & 0.0377 & 0.0650 & 0.0496 & 0.0306
\end{array} \\
& 0.08390 .02850 .00820 .01820 .0313) \text {. }
\end{aligned}
$$

Step 4: Using Eqns (7) and (8), the values of $S_{i}$ and $R_{i}$ are computed with $i=1,2, \ldots, m$.

The values of $S_{i}$ are:

$$
\begin{aligned}
& S_{1}=\sum_{j=1}^{n} w_{j}\left[\frac{a_{j}^{*}-a_{1 j}}{a_{j}^{*}-a_{j}^{-}}\right]=0.5820, \\
& S_{2}=\sum_{j=1}^{n} w_{j}\left[\frac{a_{j}^{*}-a_{2 j}}{a_{j}^{*}-a_{j}^{-}}\right]=0.5298, \\
& S_{3}=\sum_{j=1}^{n} w_{j}\left[\frac{a_{j}^{*}-a_{3 j}}{a_{j}^{*}-a_{j}^{-}}\right]=0.2778, \\
& S_{4}=\sum_{j=1}^{n} w_{j}\left[\frac{a_{j}^{*}-a_{4 j}}{a_{j}^{*}-a_{j}^{-}}\right]=0.1938, \\
& S_{5}=\sum_{j=1}^{n} w_{j}\left[\frac{a_{j}^{*}-a_{5 j}}{a_{j}^{*}-a_{j}^{-}}\right]=0.1774 ;
\end{aligned}
$$

the values of $R_{i}$ are:

$$
\begin{aligned}
& R_{1}=\max _{j}\left[w_{j}\left(\frac{a_{j}^{*}-a_{1 j}}{a_{j}^{*}-a_{j}^{-}}\right)\right]=0.1322, \\
& R_{2}=\max _{j}\left[w_{j}\left(\frac{a_{j}^{*}-a_{2 j}}{a_{j}^{*}-a_{j}^{-}}\right)\right]=0.1780,
\end{aligned}
$$




$$
\begin{aligned}
& R_{3}=\max _{j}\left[w_{j}\left(\frac{a_{j}^{*}-a_{3 j}}{a_{j}^{*}-a_{j}^{-}}\right)\right]=0.0776, \\
& R_{4}=\max _{j}\left[w_{j}\left(\frac{a_{j}^{*}-a_{4 j}}{a_{j}^{*}-a_{j}^{-}}\right)\right]=0.0428, \\
& R_{5}=\max _{j}\left[w_{j}\left(\frac{a_{j}^{*}-a_{5 j}}{a_{j}^{*}-a_{j}^{-}}\right)\right]=0.0496,
\end{aligned}
$$

where $S_{i}$ is the distance rate between the $i$ th bidder and the positive ideal solution, $R_{i}$ is the distance rate between the $i^{\text {th }}$ bidder and the negative ideal solution. And $w_{j}$ is weight of the $j^{\text {th }}$ line item.

Step 5: Applying Eqn (9), the values of $Q_{i}$, are computed with $i=1,2, \ldots, 5$ below:

$$
Q_{i}=v \frac{S_{i}-S^{*}}{S^{-}-S^{*}}+(1-v) \frac{R_{i}-R^{*}}{R^{-}-R^{*}},
$$

where $S^{-}=\max _{i} S_{i}=0.5820, S^{*}=\min _{i} S_{i}=0.1774, R^{-}=\max _{i}$ $R_{i}=0.1780, R^{*}=\min _{i} R_{i}=0.0428$, and $v$ represents the weight of the strategy of maximum group utility. When $v=0.5$, then values of $Q_{i}$ are $Q_{1}=0.8306, Q_{2}=0.9357$, $Q_{3}=0.2528, Q_{4}=0.0204, Q_{5}=0.0252$.

Step 6: According to the results in Step 5, the rank of $Q_{i}$, $i=1,2, \ldots, 5$, is $Q_{4}<Q_{5}<Q_{3}<Q_{1}<Q_{2}$.

Step 7: Since $Q_{5}-Q_{4}<1 / 16$ and $Q_{3}-Q_{4}>1 / 16$, thus the compromise set is $\left\{Q_{4}, Q_{5}\right\}$.
Step 8: According to values of $Q_{i}, i=1,2, \ldots, 5$, the order of the five bidders according to ascending order in their unbalanced bid extent is: Bidder 4, Bidder 5, Bidder 3, Bidder 1 , Bidder 2. Then the Bidder 2 is the most unbalanced, and the unbalanced bid extent of bidders 4 and 5 are relative less.

From the above analysis, the rank of the five bidders varies with the different values of $v$. Now we will give a detailed discussion for the rank result changes with different values $v$. The discussion will be shown from two perspectives: when $v$ is discrete point coordinate value and when $v$ is continuous point coordinate value.

\subsection{Sensitivity analysis when $v$ is discrete point coordinate value}

By sensitivity analysis, the changes of $v$ can lead to different orders of unbalance bidding degree, which is the key issue to the effective use of the model and the implementation of quantitative decision making (Simanaviciene \& Ustinovichius, 2010). Here eleven experiments are conducted, through assigning $v=0,0.1,0.2, \ldots, 0.8,0.9,1$ to analysis sensitive of the rank results. The values of $Q_{i}, i=$ $1,2, \ldots, 5$, and their ranks are shown in Table 2 . An intuitive representation is shown in Figure 2.

As shown in Figure 2, when $v=0,0.1,0.2,0.3,0.4,0.5$, the five bidders' rank of unbalance bid extent with descending order are: Bidder 2, Bidder 1, Bidder 3, Bidder 5, Bidder 4 . When $v=0.6,0.7$, the descending order ranking of five bidders are: Bidder 2, Bidder 1, Bidder 3, Bidder 4, Bidder 5. When $v=0.8,0.9,1$, the five bidders in descending order according to unbalance bid extent are: Bidder 1, Bidder 2, Bidder 3, Bidder 4, Bidder 5.

Table 1. Quotation data of the project (\$)

\begin{tabular}{|c|c|c|c|c|c|c|c|}
\hline Bid item no. & Quantity & Engineer's estimate & Bidder 1 & Bidder 2 & Bidder 3 & Bidder 4 & Bidder 5 \\
\hline 100 & 29 & 15000.0 & 5000.0 & 16394.0 & 16217.0 & 16554.0 & 17589.0 \\
\hline 101 & 14 & 35000.0 & 34538.0 & 5000.0 & 32326.0 & 34240.0 & 33431.0 \\
\hline 102 & 12 & 20000.0 & 18552.0 & 18704.0 & 19609.0 & 20335.0 & 19486.0 \\
\hline 103 & 30 & 80000.0 & 90000.0 & 69923.0 & 67827.0 & 72040.0 & 69380.0 \\
\hline 104 & 6 & 300000.0 & 600000.0 & 450000.0 & 324964.0 & 306527.0 & 300000.0 \\
\hline 105 & 12 & 1200.0 & 1132.0 & 1059.0 & 1006.0 & 946.0 & 1006.0 \\
\hline 106 & 30 & 89000.0 & 40000.0 & 50000.0 & 96949.0 & 87769.0 & 88806.0 \\
\hline 107 & 14 & 4500.0 & 4760.0 & 4515.0 & 4313.0 & 4533.0 & 4501.0 \\
\hline 108 & 25 & 62000.0 & 61587.0 & 67031.0 & 71043.0 & 70689.0 & 73251.0 \\
\hline 109 & 25 & 100000.0 & 98816.0 & 140000.0 & 113937.0 & 110383.0 & 109241.0 \\
\hline 110 & 7 & 5000.0 & 4957.0 & 4894.0 & 4487.0 & 4433.0 & 4350.0 \\
\hline 111 & 30 & 3400.0 & 3674.0 & 3759.0 & 3501.0 & 3505.0 & 3313.0 \\
\hline 112 & 2 & 150000.0 & 20000.0 & 172000.0 & 165000.0 & 170000.0 & 165000.0 \\
\hline 113 & 16 & 2800.0 & 2979.0 & 3114.0 & 3212.0 & 3005.0 & 2751.0 \\
\hline 114 & 18 & 7200.0 & 7851.0 & 8510.0 & 8780.0 & 8178.0 & 8078.0 \\
\hline 115 & 5 & 3600.0 & 3485.0 & 3278.0 & 3153.0 & 3005.0 & 3134.0 \\
\hline 116 & 32 & 9800.0 & 9131.0 & 9573.0 & 10217.0 & 11170.0 & 11064.0 \\
\hline & Total cost & & 13124973.0 & 13336015.0 & 13766763.0 & 13482422.0 & 13413891.0 \\
\hline
\end{tabular}

Note: this data set is derived from Arditi and Chotibhongs (2009). 
Table 2. Values of $Q_{i}$ and bidders' ranks

\begin{tabular}{|c|c|c|}
\hline$v$ & & $Q_{i}, i=1,2, \ldots, 5$ \\
\hline 0 & $Q_{1}=0.6612, Q_{2}=1.0000, Q_{3}=0.2573, Q_{4}=0.0003, Q_{5}=0.0504$ & $Q_{4}<Q_{5}<Q_{3}<Q_{1}<Q_{2}$ \\
\hline 0.1 & $Q_{1}=0.6951, Q_{2}=0.9874, Q_{3}=0.2564, Q_{4}=0.0043, Q_{5}=0.0454$ & $Q_{4}<Q_{5}<Q_{3}<Q_{1}<Q_{2}$ \\
\hline 0.2 & $Q_{1}=0.7290, Q_{2}=0.9745, Q_{3}=0.2555, Q_{4}=0.0083, Q_{5}=0.0403$ & $Q_{4}<Q_{5}<Q_{3}<Q_{1}<Q_{2}$ \\
\hline 0.3 & $Q_{1}=0.7628, Q_{2}=0.9616, Q_{3}=0.2546, Q_{4}=0.0123, Q_{5}=0.0353$ & $Q_{4}<Q_{5}<Q_{3}<Q_{1}<Q_{2}$ \\
\hline 0.4 & $Q_{1}=0.7967, Q_{2}=0.9486, Q_{3}=0.2537, Q_{4}=0.0164, Q_{5}=0.0302$ & $Q_{4}<Q_{5}<Q_{3}<Q_{1}<Q_{2}$ \\
\hline 0.5 & $Q_{1}=0.8306, Q_{2}=0.9357, Q_{3}=0.2528, Q_{4}=0.0204, Q_{5}=0.0252$ & $Q_{4}<Q_{5}<Q_{3}<Q_{1}<Q_{2}$ \\
\hline 0.6 & $Q_{1}=0.8645, Q_{2}=0.9228, Q_{3}=0.2518, Q_{4}=0.0244, Q_{5}=0.0201$ & $Q_{5}<Q_{4}<Q_{3}<Q_{1}<Q_{2}$ \\
\hline 0.7 & $Q_{1}=0.8984, Q_{2}=0.9098, Q_{3}=0.2509, Q_{4}=0.0284, Q_{5}=0.0151$ & $Q_{5}<Q_{4}<Q_{3}<Q_{1}<Q_{2}$ \\
\hline 0.8 & $Q_{1}=0.9322, Q_{2}=0.8969, Q_{3}=0.2500, Q_{4}=0.0325, Q_{5}=0.0100$ & $Q_{5}<Q_{4}<Q_{3}<Q_{2}<Q_{1}$ \\
\hline 0.9 & $Q_{1}=0.9661, Q_{2}=0.8840, Q_{3}=0.2491, Q_{4}=0.0365, Q_{5}=0.0050$ & $Q_{5}<Q_{4}<Q_{3}<Q_{2}<Q_{1}$ \\
\hline 1 & $Q_{1}=1.0000, Q_{2}=0.8710, Q_{3}=0.2482, Q_{4}=0.0405, Q_{5}=-0.0001$ & $Q_{5}<Q_{4}<Q_{3}<Q_{2}<Q_{1}$ \\
\hline
\end{tabular}
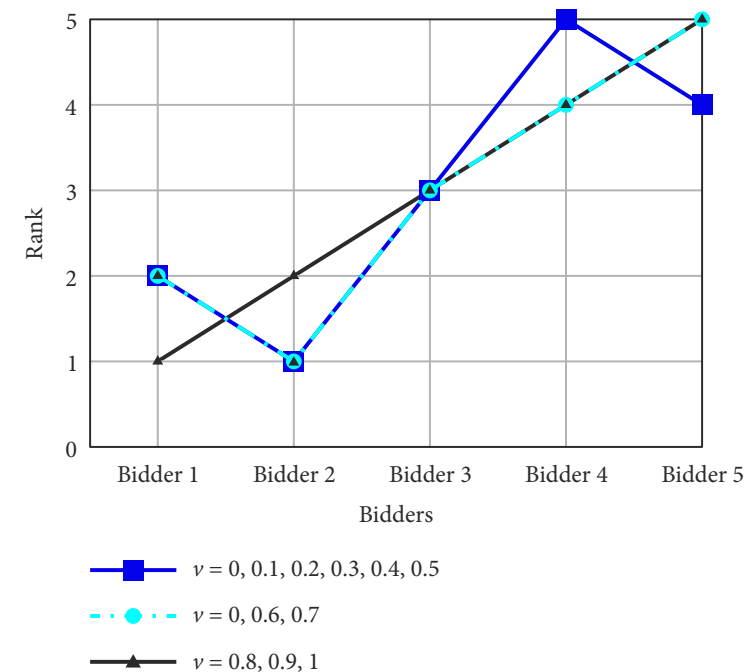

Figure 2. The different ranking results with the different values of $v$

Through above analysis, the weight of the maximum group utility plays an important role for the ranking result. And the final decision is dependent on the preference of owners.

\subsection{Sensitivity analysis when $v$ is continuous point coordinate value}

As discussed in existing research, we give a sensitive analysis for the order of the five bidders according to the unbalanced bid extent when $v$ is discrete point coordinate value in subsection 2.1. In this subsection, we proceed to do sensitivity analysis when $v$ is continuous point coordinate value.

The longitudinal and transverse axes in Figure 3 are the values of $Q_{i}$ and $v$, respectively. From the results in Steps 4 and $5, S_{i}, R_{i}$ and $Q_{i}$, are shown in Table 3 . It is noted that $Q_{i}$, change with $v$ linearly. The detailed distributions of $Q_{i}$, are descripted in Figure 3. According to different values of $v$, the lines $Q_{1}$ and $Q_{2}$ intersect at $v=$

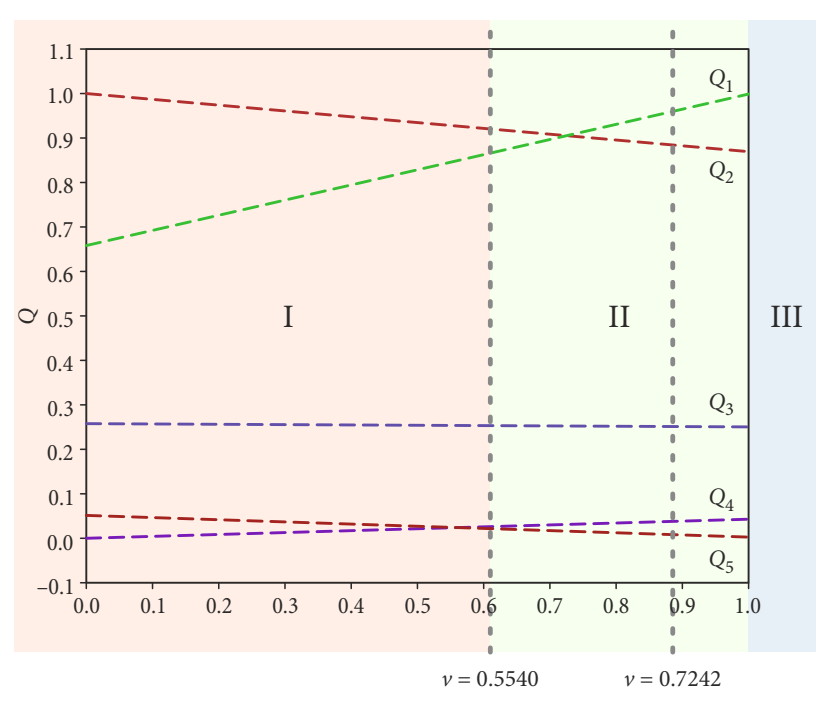

Figure 3. Sensitivity analysis of the ranking results when weight $v$ is taken different continuous value

0.7242 , the lines $Q_{4}$ and $Q_{5}$ intersect at $v=0.5540$. Therefore, the rang interval $[0,1]$ can be divided three regions: I, II and III. In region I, the rang of $v$ is interval [0, 0.5540] and the rank of $Q_{i}$ is $Q_{4}<Q_{5}<Q_{3}<Q_{1}<Q_{2}$. In region II, the rang of $v$ is interval $[0.5540,0.7242]$ and the rank of $Q_{i}$ is $Q_{5}<Q_{4}<Q_{3}<Q_{1}<Q_{2}$. And the rank of $v$ is interval $[0.7242,1]$ and the rank of $Q_{i}$ is $Q_{5}<Q_{4}<Q_{3}<Q_{2}<Q_{1}$ in region III. No matter how $v$ changes, the rank of bidders 3 is constant.

Since the value of $v$ denotes the weight of "maximum group utility", owners are more concerned with personal regret when $v$ is in region I. At this time, the rank of bidders according to descending order in their unbalanced bid extent is: Bidder 2, Bidder 1, Bidder 3, Bidder 5 , Bidder 4 , and Bidder 2 is the most unbalanced. When $v$ is in region III, the owners are more concerned with "maximum group utility", and the rank of bidders according to descending order in their unbalanced bid extent is: Bidder 1, Bidder 2, Bidder 3, Bidder 4, Bidder 5, and the Bidder 1 is the most unbalanced. When $v$ is in region II, 
Table 3. The results of calculation on $S_{i}, R_{i}$ and $Q_{i}$

\begin{tabular}{|c|c|c|c|c|l|}
\hline$S_{i}$ & & $R_{i}$ & & $Q_{i}$ & \\
\hline$S_{1}$ & 0.5820 & $R_{1}$ & 0.1322 & $Q_{1}$ & $0.3388 v+0.6612$ \\
\hline$S_{2}$ & 0.5298 & $R_{2}$ & 0.1780 & $Q_{2}$ & $1-0.129 v$ \\
\hline$S_{3}$ & 0.2778 & $R_{3}$ & 0.0776 & $Q_{3}$ & $0.2574-0.0093 v$ \\
\hline$S_{4}$ & 0.1938 & $R_{4}$ & 0.0428 & $Q_{4}$ & $0.0405 v$ \\
\hline$S_{5}$ & 0.1774 & $R_{5}$ & 0.0496 & $Q_{5}$ & $0.0503-0.0503 v$ \\
\hline$S^{*}=\min _{i} S_{i}$ & 0.1774 & $R^{*}=\min _{i} R_{i}$ & 0.0428 & & \\
\cline { 1 - 3 }$S^{-}=\max _{i} S_{i}$ & 0.5820 & $R^{-}=\max _{i} R_{i}$ & \multirow{2}{*}{0.1780} & & \multirow{2}{*}{} \\
\hline
\end{tabular}

the owners have no distinguishing preferences between "maximum group utility" and personal regret, the rank of bidders according to descending order in their unbalanced bid extent is: Bidder 2, Bidder 1, Bidder 3, Bidder 4, Bidder 5 , and the most unbalanced bid is Bidder 2 .

From the above analysis, with the different weight $v$ of group utility, the ranks of bidders are different, which means that the bidder of unbalanced bid is determined according to the attitude of owners for seriously concerning unbalanced bid. Especially, the result in the later is the same as that in Arditi and Chotibhongs (2009) and An et al. (2018). The superiority of the proposed method is that the preference of owners is taken into consideration in the identification process of unbalanced bidding. That is, the proposed method provides a flexible and straight forward way for owners to identify unbalanced bidding.

\section{Conclusions}

Unbalanced bidding presents a significant challenge faced by owners in the construction project procurement and has substantial influence on construction performance. It is unavoidable for owners to identify unbalanced bid as soon as possible. For this purpose, this study innovatively introduces decision-making method to detect unbalanced bids. The VIKOR method is employed to detect unbalanced bidding, in which the line items and bidders are considered as criteria and alternatives in MCDM, respectively. And the engineer's estimated price is chosen as evaluation benchmarking. Then relative distances between engineer's estimated price and each bidding unit price are calculated to build decision matrix. The weights of factors are determined using entropy weight method. To illustrate the effectiveness of the proposed model, an application example is tested in detecting unbalanced bidding. Finally, the sensitivity analysis about VIKOR method is given. It shows that the presented model would provide a robust decision making support for owner in identifying unbalanced bidding.

The main contributions of this paper are as follows: (1) the identification problem of unbalanced bidding is innovatively analysed using MCDM method, in which the line items and bidders are considered as criteria and alternatives in MCDM, respectively. And the engineer's estimated price is chosen as evaluation benchmarking. (2) The VIKOR method is applied to identify unbalanced bidding, since it considers all bidders' quotes and single bidder' quote, simultaneously, which can give a more reasonable result for owners. (3) The sensitivity analysis about VIKOR method is given, and the results show that the rank of bidders is varied with different preference of owners. And the proposed method of identifying unbalanced bidding exhibits the strong robustness in the identification process.

The VIKOR method, as an effective decision-making method, considers group utility and personal regret, simultaneously. Generally, owners will reject the seriously unbalanced bid appearing in bidding process. However, there are other reasons for the case of unbalanced bid that is not unbalanced on purpose by the bidder. Such as, when the bidder use new technology in its some line items, and the new technology is at the initial stage. It is natural that the cost is very higher than engineer's estimated price. In this case, if owner would like to encourage new technology, the higher bidding unit price will be accepted. On the contrary, when the bidder has a new mature technology, the cost of the work item is reduced and the lower bidding unit price is normal. Therefore, it is a complexity process for detecting unbalanced bid, and the VIKOR method we chosen should not only avoid extra cost for owners but also reconsider individual bidders occurring seriously unbalanced bid. It is more suitable to identify unbalanced bid. With the different weight $v$ of group utility, the ranks of bidders are different, which means that the bidder of unbalanced bid is determined according to the attitude of owners for seriously unbalanced bid. And the final decision is chosen follows the preferences of owners.

The identification process can be analysed within a short period of time specifically with the aid of Microsoft Excel so as to reduce delay in contract award. In the identification process of unbalanced bidding, the proposed model plays a very important role for owners as well as its limitation. For example, the engineer's estimated price is regarded as the standard bidding unit-price that is needed to be investigated further. Since the engineer's estimated price depends upon the completeness of design for a construction project. If the engineer's estimated price is 
inaccurate, the result of identification would be unreliable. Therefore, seeking the standard bidding unit-price is a direction of future research. The big data and data mining technologies should be considered in the next research for determining the standard bidding unit-price.

\section{Acknowledgements}

The authors acknowledge with gratitude the National Key R\&D Program of China(No.2018YFC0406905), MOE (Ministry of Education in China) Project of Humanities and Social Sciences (No.19YJC630078), Youth Talents Teachers Scheme of Henan Province Universities (No.2018GGJS080), the National Natural Science Foundation of China (No.71302191), the Foundation for Distinguished Young Talents in Higher Education of Henan (Humanities \& Social Sciences), China (No.2017-cxrc-023), 2018 Henan Province Water Conservancy Science and Technology Project (GG201828). This study would not have been possible without their financial support.

\section{Funding}

This work was supported by the $<$ National Key R\&D Program of China > under Grant [number 2018YFC0406905]; $<\mathrm{MOE}$ (Ministry of Education in China) Project of Humanities and Social Sciences> under Grant [number 19YJC630078]; <Youth Talents Teachers Scheme of Henan Province Universities> under Grant [number 2018GGJS080]; <the National Natural Science Foundation of China > under Grant [number 71302191], <the Foundation for Distinguished Young Talents in Higher Education of Henan (Humanities \& Social Sciences), China> under Grant [number 2017-cxrc-023].

\section{Author contributions}

Limin Su gave the idea of this paper, wrote and revised the paper; Tianze Wang presented the framework of this paper, and gave many suggestions; Huimin Li constructed the model of this paper, and gave many suggestions to improve paper; Yongchao Cao wrote the original manuscript and calculated practical examples, spelled and checked this paper; Lunyan Wang gave many suggestions to improve paper.

\section{Disclosure statement}

The authors declare no conflict of interest.

\section{References}

Abdulrahman, H., Hanid, M., \& Xiang, W. Y. (2014). Does professional ethics affect quality of construction - a case in a developing economy? Total Quality Management and Business Excellence, 25, 235-248.

https://doi.org/10.1080/14783363.2013.776764
Afshar, A., \& Amiri, H. (2010a). A min-max regret approach to unbalanced bidding in construction. KSCE Journal of Civil Engineering, 14, 653-661.

https://doi.org/10.1007/s12205-010-0972-0

Afshar, A., \& Amiri, H. (2010b). Risk-based approach to unbalanced bidding in construction projects. Engineering Optimization, 42(4), 369-385.

https://doi.org/10.1080/03052150903220964

An, X. W., Li, H. M., Zuo, J., Ojur, O., Wang, Z., \& Ding, J. (2018). Identification and prevention of unbalanced bids using the unascertained model. Journal of Construction Engineering and Management, 144(11), 05018013. https://doi.org/10.1061/(ASCE)CO.1943-7862.0001563

Arditi, D., \& Chotibhongs, R. (2009). Detection and prevention of unbalanced bids. Construction Management and Economics, 27(8), 721-732. https://doi.org/10.1080/01446190903117785

Bajari, P., Houghton, S., \& Tadelis, S. (2014). Bidding for incomplete contracts: An empirical analysis of adaptation costs. NBER Working Papers, 104(4), 1288-1319.

https://doi.org/10.1257/aer.104.4.1288

Burnett, J. E., \& Wampler, B. M. (1998). Unit price contracts: A practical framework for determining competitive bid prices. Journal of Applied Business Research, 14, 63-72. https://doi.org/10.19030/jabr.v14i3.5704

Cattell, D. (2013). The highs and lows of unbalanced bidding models. In Proceedings of CIB World Building Congress. Queensland University of Technology, Brisbane, Australia.

Cattell, D., Bowen, P., \& Kaka, A. (2004). A model to distribute mark-up amongst quotation component item prices: An outline. In Proceedings of the 2nd Postgraduate Conference on Construction Industry Development, Construction Industry Development Board (pp.154-165). Cape Town, Republic of South Africa.

Cattell, D. W., Bowen, P. A., \& Kaka, A. P. (2007). Review of unbalanced bidding models in construction. Journal of Construction Engineering and Management, 133(8), 562-573. https://doi.org/10.1061/(ASCE)0733-9364(2007)133:8(562)

Cattell, D. W., Bowen, P. A., \& Kaka, A. P. (2008). A simplified unbalanced bidding model. Construction Management and Economics, 26(12), 1283-1290. https://doi.org/10.1080/01446190802570506

Cattell, D. W., Bowen, P. A., \& Kaka, A. P. (2010). The risks of unbalanced bidding. Construction Management and Economics, 28(4), 333-344. https://doi.org/10.1080/01446191003663264

Cattell, D. W., Bowen, P. A., \& Kaka, A. P. (2011). Proposed framework for applying cumulative prospect theory to an unbalanced bidding model. Journal of Construction Engineering and Management, 137(12), 1052-1059.

https://doi.org/10.1061/(ASCE)CO.1943-7862.0000367

Christodoulou, S. E. (2008). A bid-unbalancing method for lowering a contractor's financial risk. Construction Management and Economics, 26(12), 1291-1302.

https://doi.org/10.1080/01446190802596238

Chotibhongs, R. (2011). Managing the bidding process for the construction owner-detection and prevention of unbalanced bids and collusive bids ( $\mathrm{PhD}$ thesis). Illinois Institute of Technology, Chicago.

Dong, J. Y., Yuan, F. F., \& Wan, S. P. (2017). Extended VIKOR method for multiple criteria decision-making with linguistic hesitant fuzzy information. Computers and Industrial Engineering, 112, 305-319.

https://doi.org/10.1016/j.cie.2017.07.025 
Doran, D. (2004). FMI/CMAA. Survey of construction industry ethical practices (Technical Report). McLean, VA: FMI Consulting and Construction Management Association of America.

Gates, M. (1967). Bidding strategies and probabilities. Journal of the Construction Engrg Division, 93(C01), 75-107.

Hyari, K. H. (2016). Handling unbalanced bidding in construction projects: Prevention rather than detection. Journal of Construction Engineering and Management, 142(2), 04015060. https://doi.org/10.1061/(ASCE)CO.1943-7862.0001045

Hoogenboom, J., Dale, W. S., \& Martell, C. (2006). Risk analysis and optimization of the (un)balanced bid. AACE International Transactions, R171-R176.

Hyari, K. H., Tarawneh, Z. S., \& Katkhuda, H. N. (2016). Detection model for unbalanced pricing in construction projects: A risk-based approach. Journal of Construction Engineering and Management, 142(2), 04016078.

https://doi.org/10.1061/(ASCE)CO.1943-7862.0001203

Hyari, K. H., (2017a). The controversy around unbalanced bidding in construction: Seeking a fair balance. Journal of Professional Issues In Engineering Education and Practice, 143(1), 04016015. https://doi.org/10.1061/(ASCE)EI.1943-5541.0000300

Hyari, K. H. (2017b). Owner's countermeasures to skewed bidding in construction projects: Review of current practices and proposal for new countermeasures. Journal of Construction Engineering and Management, 33(3), 04016053.

https://doi.org/10.1061/(ASCE)ME.1943-5479.0000502

Lan, S. L., Yang, C., \& Huang, G. Q. (2017). Data analysis for metropolitan economic and logistics development. Advanced Engineering Informatics, 32, 66-76.

https://doi.org/10.1016/j.aei.2017.01.003

Liu, X., Lin, L., \& Zang, D. (2009). Stochastic programming models and hybrid intelligent algorithm for unbalanced bidding problem. Computer and Information Science, 2(1), 188194. https://doi.org/10.5539/cis.v2n1p188

Liu, P. D., \& Qin, X. Y. (2017). An extended VIKOR method for decision making problem with interval-valued linguistic intuitionistic fuzzy numbers based on entropy. Informatica, 28, 665-685. https://doi.org/10.15388/Informatica.2017.151

Mandell, S., \& Nystrom, J. (2011, June). Endogenous risk in unbalanced bidding. In Conference "Management and Innovation for a Sustainable Built Environment” (MISBE2011), Delft University of Technology, Delft, Netherlands.

Manzo, F. A., \& Tell, S. (1997). Unbalanced bids and avoiding disputes relating to them (Chapter 7). In N. Sweeney (Ed.), Wiley construction law update. Hoboken, NJ: Wiley.

Renes, S. (2011). Balancing the bids, solutions for unit price auctions. Rotterdam: Tinbergen Institute.

https://doi.org/10.2139/ssrn.1775968
Renes, S. (2012). Fighting skewed bids in the EU, a comparative analysis. Rotterdam: Erasmus School of Law.

Shemshadi, A., Shirazi, H., Toreihi, M., \& Tarokh, M. J. (2011). A fuzzy vikor method for supplier selection based on entropy measure for objective weighting. Expert Systems with Applications, 38(10), 12160-12167.

https://doi.org/10.1016/j.eswa.2011.03.027

Shrestha, P. P., Shrestha, K., \& Joshi, V. (2012, November). Investigation of unbalanced bidding for economic sustainability. In International Conference on Sustainable Design, Engineering, and Construction (ICSDEC 2012) (pp. 609-616). Fort Worth, Texas, USA. https://doi.org/10.1061/9780784412688.073

Simanaviciene, R., \& Ustinovichius, L. (2010). Sensitivity analysis for multiple criteria decision making methods: TOPSIS and SAW. Procedia - Social and Behavioral Sciences, 2, 7743-7744. https://doi.org/10.1016/j.sbspro.2010.05.207

Son, J., Mack, M., \& Mattila, K. G. (2006). Nonlinear cash flow optimization model. Canadian Journal of Civil Engineering, 33, 1450-1454. https://doi.org/10.1139/106-086

Stramarcos, A., \& Cattell, D. (2013). The ethics of item pricing. In 38th Australian University Building Educators Association Conference. Australasian Universities Building Education Association (AUBEA), Auckland, New Zealand.

Stark, R. M. (1968). Unbalanced bidding models - theory. Journal of Construction Division, 94(CO2), 197-209.

Stark, R. M. (1972). Technical note. Unbalancing of tenders. Proceedings of the Institute of Civil Engineers, 51(2), 391-392. https://doi.org/org/10.1680/iicep.1972.5968

Stark, R. M. (1974). Unbalanced highway contract tendering. Operations Research Quarterly, 25(3), 373-388. https://doi.org/10.2307/3007925

Wang, W. C. (2004). Electronic-based procedure for managing unbalanced bids. Journal of Construction Engineering and Management, 130(3), 455-460. https://doi.org/10.1061/(ASCE)0733-9364(2004)130:3(455)

Wu, G. D., Duan, K. F., Zuo, J., Zhao, X. B., \& Tang, D. Z. (2017). Integrated sustainability assessment of public rental housing community based on a hybrid method of AHP-entropy weight and cloud model. Sustainability, 9(4), 603. https://doi.org/10.3390/su9040603

Yin, Y. L., Lu, Q., \& Li, B. (2010). Research on the owner's tactics to unbalanced bid under the mode of code of valuation with bill quantity of construction works. In Proceedings of IEEE 17th International Conference on Industrial Engineering and Engineering Management (IE\&EM) (pp. 249-252). Xiamen, China. https://doi.org/10.1109/ICIEEM.2010.5646655 